\title{
Desempenho de genótipos de arroz irrigado cultivados no sistema pré-germinado com inundação contínua
}

\author{
Performance of irrigated rice genotypes on a pre-germinated system with continuous flooding
}

\author{
Enio Marchezan ${ }^{1}$ Edinalvo Rabaioli Camargo ${ }^{2}$ Sérgio Iraçu Gindri Lopes ${ }^{3}$ \\ Fernando Machado dos Santos ${ }^{4}$ Simone Michelon $^{4}$
}

\section{RESUMO}

No sistema pré-germinado de cultivo do arroz irrigado, adota-se o manejo de retirada da água da lavoura, aproximadamente aos três dias após a semeadura, objetivando melhor estabelecimento das plântulas. No entanto, esta prática acarreta perda de água e nutrientes, além da reinfestação com plantas daninhas. A permanência da lâmina de água na lavoura, durante todo o ciclo da cultura, seria uma proposta de manejo capaz de minimizar estes problemas. Sendo assim, objetivou-se avaliar o desempenho de genótipos de arroz irrigado, quando submetidos ao cultivo em lâmina contínua, especialmente quanto ao acamamento de plantas, aspecto considerado limitante neste manejo de irrigação. Para tal, nos anos agrícolas de 2000/01 a 2002/03, foram conduzidos experimentos em área de várzea sistematizada, em solo classificado como Planossolo Hidromórfico eutrófico arênico. Os tratamentos foram compostos por 8,12 e 15 genótipos no primeiro, segundo e terceiro ano, respectivamente. No ano 1 , a produtividade média foi de $7279 \mathrm{~kg} \mathrm{ha}^{-1}$, sendo o genótipo IRGA 1572-11-1F-1-4-4 (8297kg ha $\mathrm{k}^{-1}$ ) o mais produtivo em valores absolutos. A porcentagem de acamamento variou entre 0 e $60 \%$ e a maioria dos tratamentos situou-se entre $0-20 \%$. Todos os genótipos exibiram acamamento de plantas, exceto El Paso L 144. No ano 2, a produtividade média foi de $8492 \mathrm{~kg}$ $\mathrm{ha}^{-1}$ e o genótipo BRS-Pelota o mais produtivo (9282 $\left.\mathrm{kg} \mathrm{ha}^{-1}\right)$, não tendo sido verificado acamamento em nenhum dos genótipos. No ano 3, a produtividade média foi de $6202 \mathrm{~kg} \mathrm{ha}$ ${ }^{1}$ e esteve relacionada à elevada porcentagem de plantas acamadas decorrente de intempéries climáticas, ocorridas na fase de maturação. Constatou-se que a produtividade dos genótipos pode ser elevada neste manejo de irrigação, mas o acamamento de plantas limita o potencial produtivo, dependendo das condições ambientais e do genótipo utilizado.

Palavras-chave: Oriza sativa L., manejo da irrigação, sistema de cultivo, acamamento, lâmina permanente.

\begin{abstract}
Under the pre-germinated system of rice growing, water is retrieved about three days after seeding in order to improve plant establishment. This practice therefore, causes water and nutrient losses and weeds reinfestation. The permanence of water in the field could minimize these problems. Experiments were conducted during the years of 2000/01 till 2002/03 aiming to evaluate the performance of permanent irrigated rice genotypes under flooding, specially for plant lodging, a limiting factor of this management system. The experiments were conducted on a lowland area in a Haplaqualf soil and the treatments were 8, 12 and 15 genotypes in the first, second, and third years, respectively. In the year 1 the mean rice yield was $7279 \mathrm{~kg} \mathrm{ha}^{-1}$ and IRGA 1572-11-1F-1-4-4 (8279kg ha $\left.\mathrm{k}^{-1}\right)$ the most productive genotype. Lodging percentage varied between 0 and $60 \%$ and for most treatments in the range from to $0-20 \%$. All genotypes presented some degree of lodging, except El Paso $L$ 144. In the year 2 the mean rice yield was $8492 \mathrm{~kg} \mathrm{ha}^{-1}$ and the most productive was BRS-Pelota (9282 $\left.\mathrm{kg} \mathrm{ha}^{-1}\right)$, and no lodging occurred among the tested genotypes. In the year 3, the mean yield was $6202 \mathrm{~kg} \mathrm{ha}^{-1}$ and was related to a high percentage of the lodging, due to climatic events during seed filling. It was observed that rice yield can be high under permanent flooding but lodging is a limiting factor depending on genotype and environmental conditions.
\end{abstract}

Key words: Oriza sativa L., irrigation management, crop system, constant flooding, lodging.

\section{INTRODUÇÃO}

O cultivo de arroz irrigado no sistema prégerminado, ocupa aproximadamente $11 \%$ das áreas

${ }^{1}$ Engenheiro Agrônomo, Professor, Doutor, Departamento de Fitotecnia, Centro de Ciências Rurais (CCR), Universidade Federal de Santa Maria (UFSM). Pesquisador do Conselho Nacional de Desenvolvimento Científico e Tecnológico (CNPq). E-mail: emarch@ccr.ufsm.br 97105-900. Santa Maria, RS. Autor para correspondência.

${ }^{2}$ Acadêmico do Curso de Agronomia, CCR, UFSM, bolsista do CNPq. Email: nalvo@mail.ufsm.br

${ }^{3}$ Engenheiro Agrônomo, Pesquisador do Instituto Riograndense do Arroz, Cachoerinha, RS.

${ }^{4}$ Acadêmico do Curso de Agronomia da UFSM, bolsista da Fundação de Amparo à Pesquisa do Estado do Rio Grande do Sul (FAPERGS). 
destinadas a esta cultura no Rio Grande do Sul, Estado responsável por cerca de 50\% da produção brasileira e quase a totalidade das áreas de Santa Catarina, que possui a maior produtividade nacional. Neste sistema, a área é inundada 20 dias antes da semeadura, que é realizada com as sementes previamente germinadas.

O manejo usualmente adotado pelos produtores que utilizam o sistema pré-germinado, consiste na retirada da água da lavoura cerca de 3 dias após a semeadura, visando melhor estabelecimento das plântulas de arroz. No entanto, esta prática acarreta perda de água e de nutrientes, além da reinfestação por plantas daninhas, especialmente o arroz vermelho.

Resultados obtidos por MACHADO et al.(2002) demonstraram que, para os sistemas prégerminado, transplante de mudas e mix de prégerminado há, por ocasião da formação da lâmina de água, um consumo de $1285 \mathrm{~m}^{3} \mathrm{ha}^{-1}$, o que representa de 15 a $20 \%$ do volume consumido durante o ciclo da cultura, sem contabilizar as precipitações pluviais ocorridas no período. Com isso, a realização da drenagem inicial provoca a perda de considerável volume de água, recurso limitante em algumas regiões produtoras e principal item na composição do custo de produção.

Além disso, ao proceder a drenagem são carreadas partículas sólidas em suspensão na água e, por conseqüência, são perdidos os nutrientes adsorvidos a estas ou presentes na solução. Estudos realizados por MARCHEZAN et al.(2002b), visando quantificar as perdas de nutrientes na água drenada em sistemas de implantação de arroz com alagamento inicial do solo, após três anos de estudo, obtiveram para o sistema pré-germinado, perdas de 3,78;0,1 e $4,83 \mathrm{~kg} \mathrm{ha}^{-1}$, respectivamente para $\mathrm{N}_{\text {total }}, \mathrm{P}$ e $\mathrm{K}$, valores considerados aceitáveis de acordo com os padrões vigentes.

No entanto, em trabalho realizado por WEBER et al. (2003) as concentrações de nutrientes encontrados nas água de drenagem inicial dos sistemas pré-germinado, mix de pré-germinado e transplante de mudas foram mais elevadas e, na média dos sistemas, situaram-se em 5,02; 2,06; 10,33; 6,38; 3,51 e 2,56kg ha- ${ }^{-1}$ para $\mathrm{N}, \mathrm{P}, \mathrm{K}, \mathrm{Ca}, \mathrm{Mg}$ e $\mathrm{Fe}$, respectivamente. Estes resultados demonstram que as perdas podem afetar a sustentabilidade do sistema e os autores relatam a necessidade de reduzi-las através do maior período de tempo entre adubação e o preparo final do solo e a drenagem subseqüente, tempo esse, necessário para que ocorra a decantação das partículas coloidais em suspensão. Estas perdas também podem ser evitadas, através do manejo da água de irrigação, com manutenção de lâmina contínua, desde a inundação da área.

O sistema pré-germinado, associado ao manejo da água, através da manutenção contínua de lâmina de água, é uma alternativa eficiente no controle de plantas invasoras, especialmente o arroz vermelho. Neste sentido, trabalho de AVILA et al. (2000) avaliando sistemas de cultivo de arroz irrigado para o controle de arroz vermelho, concluíram que a semeadura do arroz em solo inundado, seja no sistema prégerminado, mix de pré-germinado ou transplante de mudas, proporciona maior controle desta invasora.

Por outro lado, o acamamento de plantas pode ser potencializado com a adoção de lâmina contínua. Para ISHIY et al. (1999), este é o principal parâmetro a ser observado quando se avalia este manejo de irrigação, pois dificulta a colheita, interferindo no potencial produtivo e na qualidade de grãos. Relatos de KONO (1995) indicam que o acamamento de plantas ocorre em determinados anos, em alguns sistemas de cultivo e em alguns cultivares de arroz, evidenciando que há diversos mecanismos envolvidos neste processo.

Assim, a permanência de água nos quadros de cultivo, posiciona-se como uma proposta de manejo capaz de minimizar as perdas de água e de nutrientes, bem como, proporcionar controle mais eficiente às plantas invasoras. Com isso, conduziu-se um experimento a campo durante três safras agrícolas, objetivando avaliar o comportamento de genótipos de arroz irrigado, no sistema pré-germinado com inundação contínua, especialmente quanto a produtividade e ao acamamento de plantas.

\section{MATERIAL E MÉTODOS}

O experimento foi instalado nas safras agrícolas 2000/01 (Ano 1), 2001/02 (Ano 2) e 2002/03 (Ano 3), em área de várzea sistematizada do Departamento de Fitotecnia da Universidade Federal de Santa Maria, em um Planossolo Hidromórfico eutrófico arênico, com as seguintes características físico-químicas: argila: $25 \%$; $\mathrm{pH}_{(\mathrm{H} 2 \mathrm{O})}$ : 5,2; $\mathrm{P}: 9,7 \mathrm{mg} \mathrm{L}^{-1}$; $\mathrm{K}: 48 \mathrm{mg} \mathrm{L}^{-1} ; \mathrm{Ca}+\mathrm{Mg}: 4,5 \mathrm{cmol}_{\mathrm{c}} \mathrm{L}^{-1} ; \mathrm{H}+\mathrm{Al}: 4,1 \mathrm{cmol}_{\mathrm{c}} \mathrm{L}^{-1}$ e M.O.: $1,9 \%$. As parcelas possuíam dimensão de $3 \times 4$ $\mathrm{m}$, totalizando uma área útil de $12 \mathrm{~m}^{2}$. O delineamento experimental utilizado foi de blocos ao acaso, com quatro repetições, sendo os tratamentos compostos por oito genótipos no ano 1, doze no ano 2 e quinze no ano 3, listados nas tabelas 1, 2 e 3, respectivamente.

Dentre os genótipos testados, encontramse cultivares que estão registradas para produção comercial, bem como, linhagens em fase final de 
Tabela 1 - Produtividade, esterilidade de espiguetas, grãos inteiros, plantas acamadas e umidade de colheita em genótipos de arroz irrigado no sistema pré-germinado, sob lâmina de água contínua, safra 2000/01. Santa Maria, RS. 2003.

\begin{tabular}{|c|c|c|c|c|c|}
\hline Genótipos & $\begin{array}{l}\text { Produtividade } \\
\qquad\left(\mathrm{kg} \mathrm{ha}^{-1}\right)\end{array}$ & Esterilidade (\%) & Grãos inteiros (\%) & $\begin{array}{c}\text { Classes de } \\
\text { acamamento }^{1}\end{array}$ & Umidade de colheita (\%) \\
\hline IRGA 1572-11-1F-1-4-4 & $8297 a^{*}$ & $11 \mathrm{~b}$ & $57,5 \mathrm{~b}$ & 1 & 18,9 \\
\hline BR-IRGA 410 & $7700 \mathrm{a}$ & $8,4 \mathrm{~b}$ & $53,3 \quad \mathrm{c}$ & 1 & 20,2 \\
\hline IRGA $1598-3-2 F-1-3-1$ & $7651 \mathrm{a}$ & $8,5 \mathrm{~b}$ & $57,6 \mathrm{~b}$ & 1 & 19,8 \\
\hline IRGA 1581-8-5-1-2 & $7537 \mathrm{a}$ & $10 \mathrm{~b}$ & 58,6 b & 1 & 18,7 \\
\hline IRGA 419 & $6974 b$ & $15 \mathrm{a}$ & $56,6 \quad b$ & 1 & 18,6 \\
\hline IRGA 417 & $6929 \mathrm{~b}$ & $10 \mathrm{~b}$ & $60,5 \mathrm{a}$ & 2 & 23,3 \\
\hline El Paso L 144 & $6803 \mathrm{~b}$ & $14 \mathrm{a}$ & $61,4 \mathrm{a}$ & 0 & 23,4 \\
\hline BRS-Taim & $6326 \mathrm{~b}$ & $17 \mathrm{a}$ & $53,6 \quad \mathrm{c}$ & 3 & 18,8 \\
\hline Média & 7279 & 12 & 57,4 & 1 & 20,2 \\
\hline C.V. $(\%)$ & 6,8 & 12,7 & 1,56 & -- & ----- \\
\hline
\end{tabular}

* Médias não ligadas pela mesma letra diferem entre si pelo teste de Scott \& Knott a 5\% de probabilidade de erro.

avaliação cedidas pelo programa de fitomelhoramento do Instituto Rio Grandense do Arroz. O desenvolvimento de genótipos e a contínua avaliação, fazem com que ao passar dos anos, novas linhagens sejam incluídas nos testes de campo, bem como, aquelas que não tiveram desempenho satisfatório em ensaios regionais sejam excluídas, justificando a variação do seu número entre os anos. Desta forma, durante as três safras agrícolas e dentre os genótipos estudados, BR-IRGA 410, IRGA 419 e IRGA 1598-3-2F1-3-1 foram os que permaneceram no experimento.
No ano 1, o preparo do solo foi realizado antes da entrada de água, através de gradagens e posterior aplainamento superficial da área. Já com o solo inundado, efetuou-se a adubação de base, aos 10 dias antes da semeadura, conforme recomendação oficial da pesquisa. No ano 2, após o preparo do solo, transcorreu um período de aproximadamente 15 dias até a entrada de água. Este intervalo de tempo propiciou a emergência de plantas invasoras, que foram eliminadas através de dessecação com herbicida de ação total, aplicado antes da inundação da área. A adubação de

Tabela 2 - Produtividade, esterilidade de espiguetas, grãos inteiros e umidade de colheita em genótipos de arroz irrigado no sistema prégerminado, sob lâmina de água contínua, safra 2001/02. Santa Maria, RS. 2003.

\begin{tabular}{|c|c|c|c|c|}
\hline Genótipos & $\begin{array}{l}\text { Produtividade } \\
\qquad\left(\mathrm{kg} \mathrm{ha}^{-1}\right)\end{array}$ & $\begin{array}{c}\text { Esterilidade } \\
(\%)\end{array}$ & $\begin{array}{c}\text { Grãos inteiros } \\
(\%)\end{array}$ & Umidade de colheita (\%) \\
\hline BRS-Pelota & $9282 \mathrm{a}^{*}$ & $12 \mathrm{c}$ & $63,7^{\mathrm{ns}}$ & $20,7^{\mathrm{ns}}$ \\
\hline BRS-Taim & $9140 \mathrm{a}$ & $18 \mathrm{a}$ & 64,3 & 17,6 \\
\hline IRGA 420 & $9048 \mathrm{a}$ & $15 \mathrm{~b}$ & 64,1 & 18,8 \\
\hline BR-IRGA 410 & 8966 a & $11 \mathrm{c}$ & 63,4 & 21,4 \\
\hline IRGA $1572-2-2-4-3$ & 8880 a & $19 \mathrm{a}$ & 65,0 & 18,5 \\
\hline IRGA $1598-3-2 F-1-3-1$ & $8830 \mathrm{a}$ & $9 \quad \mathrm{c}$ & 66,1 & 19,1 \\
\hline IRGA 1598-7-2F-1-3-2 & $8505 \mathrm{a}$ & $18 \mathrm{a}$ & 65,3 & 18,6 \\
\hline IRGA 419 & 8476 a & $15 \mathrm{~b}$ & 66,3 & 19,6 \\
\hline IRGA 440-22-3-6-2F-2 & $8456 \mathrm{a}$ & $10 \mathrm{c}$ & 66,6 & 16,6 \\
\hline IRGA 440-49-2-2-5 & $7726 \mathrm{~b}$ & $\mathrm{c}$ & 63,3 & 18,6 \\
\hline IRGA $1832-7-2 \mathrm{C}-1-\mathrm{MF}-2-1$ & $7517 \mathrm{~b}$ & $14 \mathrm{c}$ & 67,4 & 20,6 \\
\hline IRGA 959-1-2-2F-5-2-4-D5 & $7076 \mathrm{~b}$ & $17 \mathrm{a}$ & 64,9 & 19,7 \\
\hline Média & 8492 & 14 & 65,0 & 19 \\
\hline $\mathrm{CV}(\%)$ & 9,25 & 10,07 & 9,32 & 3,54 \\
\hline
\end{tabular}

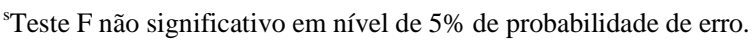

* Médias não ligadas pela mesma letra diferem entre si pelo teste de Scott \& Knott a 5\% de probabilidade de erro. 
Tabela 3.- Produtividade, grãos por panícula, esterilidade de espiguetas e massa de mil grãos em genótipos de arroz irrigado no sistema pré-germinado, sob lâmina de água contínua, safra 2002/03. Santa Maria, RS. 2003.

\begin{tabular}{llll}
\hline Genótipos & $\begin{array}{c}\text { Produtividade } \\
\left(\mathrm{kg} \mathrm{ha}^{-1}\right)\end{array}$ & $\begin{array}{c}\text { Grãos por } \\
\text { panícula }\end{array}$ & Esterilidade (\%) \\
\hline IRGA 440-22-3-6-2F-1C & $7345 \mathrm{a}^{*}$ & $79 \mathrm{c}$ & $19 \mathrm{~b}$ \\
CT 8008-3-5-6P-1 & $6843 \mathrm{a}$ & $81 \mathrm{c}$ & $16 \mathrm{~b}$ \\
IRGA 1832-5-5C-MF-2-2 & $6644 \mathrm{a}$ & $77 \mathrm{c}$ & $22 \mathrm{a}$ \\
IRGA 417 & $6580 \mathrm{a}$ & $91 \mathrm{~b}$ & $11 \mathrm{~b}$ \\
IRGA 420 & $6505 \mathrm{a}$ & $67 \mathrm{~d}$ & $26 \mathrm{a}$ \\
RGA 1832-7-2C-1-MF-2-1 & $6371 \mathrm{a}$ & $93 \mathrm{~b}$ & $17 \mathrm{~b}$ \\
IRGA 419 & $6349 \mathrm{a}$ & $84 \mathrm{c}$ & $23 \mathrm{a}$ \\
BR-IRGA 410 & $6293 \mathrm{a}$ & $118 \mathrm{a}$ & $15 \mathrm{~b}$ \\
IRGA 1572-2-2-4-3 & $6249 \mathrm{a}$ & 72 & $27 \mathrm{a}$ \\
IRGA 2003-2-8C-MF-4-3 & $6069 \mathrm{a}$ & $84 \mathrm{c}$ & $25 \mathrm{a}$ \\
IRGA 1598-3-2F-1-3-1 & $6029 \mathrm{a}$ & $91 \mathrm{~b}$ & $19 \mathrm{~b}$ \\
IRGA 1578-7-3F-1-3-2 & $5880 \mathrm{~b}$ & $65 \quad \mathrm{~d}$ & $17 \mathrm{~b}$ \\
IRGA 1782-2-1C-2A & $5786 \mathrm{~b}$ & $70 \mathrm{~d}$ & $24 \mathrm{a}$ \\
IRGA 959-1-2-2F-5-2-5-B-1 & $5104 \mathrm{~b}$ & $96 \mathrm{~b}$ & $22 \mathrm{a}$ \\
El Paso L 144 & $4979 \mathrm{~b}$ & $108 \mathrm{a}$ & $25 \mathrm{a}$ \\
Média & 6202 & 85 & 20,5 \\
CV (\%) & 8,32 & 12,27 & 16,49 \\
\hline
\end{tabular}

* Médias não ligadas pela mesma letra diferem entre si pelo teste de Scott \& Knott a 5\% de probabilidade de erro.

base foi aplicada 15 dias após a semeadura, quando a cultura já estava plenamente estabelecida, evitando ao máximo a saída de água com os nutrientes do sistema, principalmente em situações de precipitações elevadas.

No ano 3, em decorrência do excesso de chuva, realizou-se o preparo do solo com umidade elevada, não se obtendo a eliminação total das plantas invasoras. Desta forma, antes do início da irrigação realizou-se a pulverização com os herbicidas glyfhosate e metsulfuron, nas dosagens de 1080 e $2 \mathrm{~g}$.i.a ha ${ }^{-1}$, respectivamente. Como não houve reinfestação das parcelas com plantas invasoras, não foi necessário aplicar herbicida em pós-emergência. A adubação de base, semelhante ao manejo adotado no ano 2 , foi executada vinte dias após a semeadura.

Nas três safras agrícolas, a semeadura $\left(120 \mathrm{~kg} \mathrm{ha}^{-1}\right)$ foi realizada manualmente a lanço nos dias 24/11/00, 10/11/01 e 19/11/02 após vinte dias de inundação da área. Nos anos 1 e 2, o controle de plantas daninhas de folhas largas e ciperáceas foi executado pela aplicação de herbicidas pósemergentes, azimsulfuron e metsulfuron, nas dosagens de 5 e 2 g.i.a ha ${ }^{-1}$, respectivamente. No ano 3, devido ao acamamento de plantas e a ocorrência de doenças, foi executada a aplicação do fungicida tebuconazole, na dosagem de 150 g.i.a ha ${ }^{-1}$.

A irrigação por inundação foi contínua deste o período de 20 dias antes da semeadura até a colheita, não sendo realizada a drenagem inicial, que é preconizada para o sistema prégerminado. Por ocasião da semeadura, a água encontrava-se limpa, sem a presença de sólidos em suspensão que impedissem a passagem de luz às sementes. Mantevese uma lâmina de aproximadamente $5 \mathrm{~cm}$ de altura durante a fase inicial de estabelecimento das plântulas, elevandose após, para cerca de $10 \mathrm{~cm}$.

Os parâmetros avaliados nos experimentos conduzidos no ano 1 e 2 foram: produtividade, acamamento, grãos inteiros, esterilidade de espiguetas e umidade de colheita. No ano 3, o elevado percentual de plantas acamadas, que acarretou na permanência das panículas por um longo período submersas à lâmina de água ou mesmo em contato com o solo, fez com que a porcentagem de grãos inteiros não fosse avaliada, visto que esta condição teria interferência direta nos resultados.

Para a avaliação de acamamento foram consideradas as seguintes classes: [0] 0\% de acamamento; [1] 1 a 20\% de acamamento; [2] 21 a $40 \%$ de acamamento; [3] 41 a $60 \%$ de acamamento; [4] 61 a $80 \%$ de acamamento e [5] 81 a $100 \%$ de acamamento. Por ocasião da colheita, foi feita a observação visual na área das parcelas experimentais, relacionando a porcentagem de plantas acamadas com a classe correspondente.

Os dados obtidos nos experimentos foram submetidos à análise de variância e as médias comparadas pelo teste de Scott \& Knott em nível de $5 \%$ de probabilidade de erro. Os resultados expressos em porcentagem foram transformados por ocasião da análise, para arco seno, com o propósito de normalizar a sua distribuição.

\section{RESULTADOS E DISCUSSÃO}

Nas três safras agrícolas, a cultura estabeleceu-se plenamente e, de forma geral, as populações de plantas apresentaram-se uniformes, com aproximadamente 300 plantas $\mathrm{m}^{-2}$. Esta observação confirma a possibilidade de desenvolvimento satisfatório das plântulas de arroz no sistema prégerminado mesmo sem a realização da drenagem inicial. Para isto, é necessário que a superfície do solo esteja perfeitamente nivelada e que a lâmina de água seja uniforme. 
A permanência de lâmina de água contínua, desde o período de inundação da área até a colheita, associado ao adequado preparo do solo, auxiliou no controle das plantas invasoras gramíneas, especialmente o capim-arroz, não sendo necessário realizar controle nas três safras agrícolas. Cabe ressaltar que a área onde os experimentos foram conduzidos não apresentava infestação por arroz vermelho e, com isso, não se pôde observar o efeito do manejo de água adotado sobre esta planta invasora.

No ano 1, a produtividade média do experimento foi de $7279 \mathrm{~kg} \mathrm{ha}^{-1}$, havendo comportamento diferenciado entre os genótipos testados (Tabela 1). O genótipo IRGA 1572-11-1F-1-44 obteve a maior produtividade $\left(8297 \mathrm{~kg} \mathrm{ha}^{-1}\right)$ não diferindo estatisticamente do BR-IRGA 410, IRGA 1598-3-2F-1-3-1 e IRGA 1581-8-5-1-2. O acamamento de plantas situou-se entre as classes 0 e 3 e a média do ensaio ficou na classe 1 . Os genótipos mais produtivos, bem como o IRGA 419, cultivar recomendada para este sistema de cultivo, apresentaram de 1 a $20 \%$ de acamamento, correspondente a classe 1 . A cultivar BRS-Taim situouse na classe 3 , com 41 a $60 \%$ de acamamento. As plantas da cultivar El Paso L 144 não acamaram.

No ano 2, a produtividade média do ensaio foi de $8492 \mathrm{~kg} \mathrm{ha}^{-1}$, com o genótipo BRS-Pelota alcançando, em valores absolutos, a maior produtividade $\left(9282 \mathrm{~kg} \mathrm{ha}^{-1}\right)$ e diferindo estatisticamente dos genótipos IRGA 440-49-2-2-5, IRGA 1832-7-2C-1-MF-2-1 e IRGA 959-1-2-2F-5-2-4-D5 (Tabela 2). Nesta safra, não ocorreu acamamento de plantas em nenhum genótipo testado.

A qualidade física do arroz, expressa através da porcentagem de grãos inteiros, apresentou média de 57 e $65 \%$, respectivamente no ano 1 e 2 . Os valores baixos de grãos inteiros obtidos no primeiro ano, especialmente para as cultivares BRS-Taim e BR-IRGA 410, possivelmente estejam relacionados ao acamamento da primeira e a exigência de colheita com grau de umidade mais elevado da segunda.

No ano 3, a produtividade variou entre 4979 a $7345 \mathrm{~kg} \mathrm{ha}^{-1}$ e dentre os genótipos estudados, $73 \%$ obtiveram comportamento similar para este parâmetro após o teste de média (Tabela 3). Neste ano, a produtividade média foi de $6202 \mathrm{~kg} \mathrm{ha}^{-1}$, valor inferior aos anos anteriores, e fortemente relacionado à elevada porcentagem de plantas acamadas, decorrente de dois temporais ocorridos nos dias 28/02/03 e 01/03/ 03 , com chuva de alta intensidade e ventos com rajadas de até $120 \mathrm{~km} \mathrm{~h}^{-1}$, conforme dados registrados pela estação meteorológica de Santa Maria, localizada cerca de 500m da área experimental. Nesta ocasião, a maioria dos genótipos encontravam-se na fase de enchimento de grãos.

Esta intempérie foi responsável pelo acamamento total de praticamente todos os genótipos, exceto IRGA 959-1-2-2F-5-2-5-B-1, único que ainda se encontrava em pleno florescimento. $\mathrm{O}$ elevado porcentual de espiguetas estéreis, associado ao acamamento das plantas, contribuiu para a redução da produtividade. No ano 3, obteve-se, na média do ensaio, 20,5\% de esterilidade, ao passo que, nos anos 1 e 2 as porcentagens foram de 12 e $14 \%$, respectivamente.

A utilização de lâmina de água contínua permitiu a obtenção de produtividades elevadas nos dois primeiros anos de experimento, resultados estes que vêm de encontro aos obtidos por MARCHEZAN et al.,(2002a) que, ao estudarem manejos da água de drenagem, incluindo irrigação com lâmina contínua, obtiveram produtividades estatisticamente semelhantes, com valores médios de $7260 \mathrm{~kg} \mathrm{ha}^{-1}$.

Ainda MARCOLIN \& MACEDO (2001), avaliando o efeito da lâmina de água na população inicial e final de plantas e no rendimento de grãos no sistema pré-germinado, concluíram que a drenagem inicial pode ser feita até cinco dias após a semeadura sem redução da produtividade, bem como, que não há necessidade de realizá-la, caso o solo tenha sido preparado sem a presença de lâmina de água.

Dos genótipos testados nos três anos, utilizando-se as produtividades médias dos experimentos como parâmetro de comparação, observase que a cultivar BR-IRGA 410 foi a que sempre apresentou produtividade acima da média. Além desta, a linhagem IRGA 1598-3-2F-1-3-1 situou-se entre àquelas classificadas como mais produtivas após a execução do teste de média. No entanto, alguns genótipos apresentaram comportamento diferenciado de uma safra para outra, como foi o caso do BRS-Taim, que obteve a menor produtividade no ano 1 e a maior produtividade no ano 2 , caracterizando a influência de condições climáticas.

No ano 1, obtiveram-se respostas distintas dos genótipos em relação ao acamamento das plantas, o que pode estar relacionado com suas características de resistência. Não obstante, a não ocorrência de acamamento no ano 2 , indica que existem outros fatores interagindo, além do fator genético. Obviamente as condições climáticas interagem e influenciam este parâmetro, conforme foi observado no ano 3, quando a ocorrência de ventos fortes associados à chuva proporcionou acamamento das plantas.

Diversos fatores são relatados como causadores de acamamento na cultura do arroz, dentre 
estes: condições ambientais, intensidade de chuvas e ventos, características fenotípicas do genótipo (peso da panícula, altura de planta, robustez do colmo, número de panículas por unidade de área e quantidade e distribuição das raízes), propriedades do solo e condições de cultivo (KONO, 1995; WATANABE, 1997). Para estes autores, o acamamento é determinado pelo balanço entre as forças indutoras e a resistência da planta.

\section{CONCLUSÃO}

O manejo de irrigação adotado permite a obtenção de produtividades elevadas, mas o acamamento de plantas pode ser limitante sendo ambas as características influenciadas pelo genótipo utilizado e pelo ano agrícola.

A cultivar BR-IRGA 410 e a linhagem IRGA 1598-3-2F-1-3-1, estudadas nos três anos, obtêm respostas produtivas satisfatórias no manejo de lâmina contínua.

\section{REFERÊNCIAS BIBLIOGRÁFICAS}

AVILA, L.A. de et al. Sistemas de cultivo de arroz irrigado para o controle de arroz-vermelho. Agrop Clima Temperado, Pelotas, v.3, n.2, p.165-173. 2000.

ISHIY, T.; SCHIOCCHET, M.; NOLDIN J.A. Comportamento de linhagens e cultivares de arroz submetidas a condições de inundação permanente. In: REUNIÃO DA CULTURA DO ARROZ IRRIGADO, 23., 1999, Pelotas, RS. Anais... Pelotas : Embrapa Clima Temperado, 1999. p.117-119.

KONO, M. Phsysiological aspects of lodging. In: MATSUO, T. et al. Science of the rice plant. Tokyo, Japan : Nobunkyo, 1995. V.2, cap.4, p.971-982.

MACHADO, S.L.O. et al. Determinação do consumo de água em cinco sistemas de cultivo de arroz irrigado. In: CONGRESSO DA CADEIA PRODUTIVA DE ARROZ, 1.; REUNIÃO NACIONAL DE PESQUISA DE ARROZ, 7., 2002, Florianópolis, SC. Anais... Santo Antônio de Goiás : Embrapa Arroz e Feijão, 2002. p.336-339.

MARCHEZAN, E. et al. Manejo da irrigação do arroz por inundação usando sementes pré-germinadas. Eng Agr, Jaboticabal, v.22. n.3, p.339-346. 2002a.

MARChEZAN, E. et al. Perda de nutrientes na água de drenagem inicial na cultura do arroz irrigado. In: CONGRESSO DA CADEIA PRODUTIVA DE ARROZ, 1.; REUNIÃO NACIONAL DE PESQUISA DE ARROZ, 7., 2002. Florianópolis, SC. Anais... Santo Antônio de Goiás : Embrapa Arroz e Feijão, 2002b. p.680-683.

MARCOLIN, E.; MACEDO, V.R.M. Manejo da drenagem inicial e sua relação com a população de plantas e rendimento de grãos de arroz no sistema pré-germinado. I n: CONGRESSO BRASILEIRO DE ARROZ IRRIGADO, 2.; REUNIÃO DA CULTURA DO ARROZ IRRIGADO, 24., 2001, Porto Alegre, RS. Anais... Porto Alegre : Instituto Rio Grandense do Arroz, 2001. p.227-228.

WATANABE, T. Lodging resistance. In: MATSUO, T. et al. Science of the rice plant. Tokyo, Japan : Nobunkyo, 1997. V.3, cap.4, p.567-577.

WEBER, L. et al. Cultivares de arroz irrigado e nutrientes na água de drenagem em diferentes sistemas de cultivo. Ciência Rural, Santa Maria, v.33, n.1, p. 27-33. 2003. 